\title{
NA ESCURIDÃO DA CENSURA, SURGIU UMA LUZ: LAMPIÃO DA ESQUINA E A IMPRENSA ALTERNATIVA (1978-1981)
}

\begin{abstract}
JOSEPH BIANCHI CAVA ${ }^{1}$
Resumo: Sem pormenorizar, o presente artigo apresenta como foi implementada a censura prévia, no Brasil, durante a Ditadura Civil-militar, além de contextualizar a origem da Imprensa Alternativa e Homossexual nesse mesmo contexto. Assim sendo, após um levantamento bibliográfico para a realização de um projeto de Iniciação Científica sobre o jornal Lampião da Esquina, relataram-se os mecanismos utilizados pelo regime autoritário para controlar as produçóes midiáticas, possuindo como recorte, a imprensa. $\mathrm{O}$ artigo também estabelece um diálogo entre os tabloides alternativos, das décadas de 1960 a 1980, com o surgimento do periódico Lampião e do grupo SOMOS.
\end{abstract}

Palavras-chave: Imprensa Alternativa; Lampião da Esquina; Censura; Ditadura Civil-Militar.

A história da imprensa brasileira, no período dos anos de 1960 até 1980, é perpassada pelo algoz governo militar (1964-1985) e suas respectivas características autoritárias. Nesse contexto, a Ditadura Civil-militar restringiu as liberdades individuais, perseguiu e torturou opositores, valeu-se da censura e defendeu concepções morais e éticas em sintonia com valores das classes dominantes e conservadoras. Além disso, o autor Renan Quinalha denomina tal época com o termo ditadura "hetero-militar” (QUINALHA, 2018, p. 31), já que o autoritarismo não se pautava apenas no âmbito político, mas também reprimia as manifestações sexuais divergentes das impostas pela sociedade andro-heterocentrada ${ }^{2}$ brasileira.

$1 \quad$ Estudante de Licenciatura em História, na Unesp-Assis.

jbianchicava@gmail.com

2 O sistema androcêntrico se estabelece em bases assimétricas de poder hierárquicos que oprimem as mulheres. A sexualidade está orientada pela perspectiva da complementaridade entre homens e mulheres, com base no sexo biológico. Além disso, valores e hierarquias sociais se relacionam ao sexo biológico, impulsionando todos em direção à sexualidade “positiva”, ou seja, à heterossexualidade.” (PINAFI, 2010, p.333) 
Em 1964, momento em que o presidente João Goulart foi deposto de seu cargo, por meio de um golpe articulado entre o Exército e setores conservadores da sociedade, o novo governo recebeu inicialmente apoio da imprensa convencional ${ }^{3}$. Segundo Marialva Barbosa, “a imprensa, quase de forma unânime (a exceção representativa é a do jornal Última Hora), dá vivas à ação dos militares, afirmando, em inflamados editoriais, a legitimidade do movimento" (BARBOSA, 2007, p. 184). Contudo, ainda na concepção da autora, nos anos subsequentes a maioria desses jornais passariam de aliados para opositores do regime.

Esse período em questão, de 1964 a 1985, é marcado pela implementação do controle da informação sobre todos os meios de comunicação. Conhecido como censura, esse processo teve forte impacto nas produções jornalísticas da época. Segundo Barbosa:

\begin{abstract}
A censura política, conduzida em momentos de autoritarismo, geralmente age de forma intermitente, mas não constante, e de maneira diferenciada em relação aos veículos de comunicação. Desde o golpe de 1964, informa Aquino (Idem: 516), instauram-se mecanismos para controlar as informações veiculadas. Há a preocupação com o armazenamento de informações e com a divulgação que a imprensa poderia produzir para o público. Assim, em 1964, cria-se o Serviço Nacional de Informações (SNI) e, no final da década, estruturam-se os centros de informação do Exército (CIE), da Aeronáutica (CISA) e se rearticula o centro da Marinha (CENIMAR) (D'ARAÚJO, 1995 apud BARBOSA, 2007, p. 187)
\end{abstract}

Desse modo, parafraseando Barbosa (2007), a forma mais comum de controle da informação era por meio de telefonemas, bilhetes ou visitas de oficiais do governo às redações de jornais, nas quais proibiam a divulgação de determinadas notícias. Assim sendo, em conformidade com Aquino, ocorria nesse momento o início da autocensura, "na medida em que, após a transmissão das proibiçôes, cabia ao órgão de divulgação acatá-las, censurando internamente a divulgação de determinadas notícias" (AQUINO, 1999, p.22). Todavia, após a outorga do AI-5 (13 de dezembro, $1968^{4}$ ) pelo presidente militar Costa e Silva, a censura brasileira se moldou em parâmetros mais rígidos e institucionalizados do que anteriormente. Além dis-

3 "A imprensa convencional organiza-se em torno dos princípios liberais, estruturando-se como uma empresa capitalista que pode atingir pequeno, médio e grande porte (e, nesse caso, é chamada de grande imprensa).” (AQUINO, 1999, p.122)

$4 \quad$ "O Executivo publicou o AI-5, concentrando e conferindo excepcionalidade maior ao presidente; limitando ou extinguindo liberdades democráticas e suspendendo garantias constitucionais. Ao contrário dos atos institucionais anteriores, não havia prazo estipulado para sua vigência. O Congresso Nacional foi fechado por tempo indeterminado." (AQUINO, 1999, p.206) 
so, é válido ressaltar que durante o intervalo entre 1972 e 1975 ocorreu a radicalização da cen sura prévia no país.

Em contrapartida às questóes relatadas, alguns intelectuais, professores e jornalistas articularam-se e iniciaram a produção de tabloides, logo chamados de alternativos, com o intuito de resistir à situação vigente, assim como explicou Kucinski, esse modo de imprensa seria caracterizado pelo seu surgimento em momentos em que a sociedade passava por dificuldades, no qual se divergia das "políticas dominantes" e possuíam a intenção de "protagonizar as transformações sociais” em meio aos anos de 1960 e 1970. (KUCINSKI, 2003, p.13)

Ademais, outros autores trabalharam com o conceito de imprensa alternativa. Aquino (1999) cita alguns deles: quando participava da produção do Catálogo da Imprensa Alternativa, Leila Míccolis caracterizou esse estilo de periódico como aquele que apresenta algum tipo de contestação contracultural; voltado para um viés mais econômico, Ciro Marcondes Filho definiu alternativo como o que não reproduz relações diretas com o capital; Sônia Virgínia Moreira defendeu que são os periódicos não ligados à grande imprensa; Raimundo Rodrigues Pereira definiu essa maneira de produção jornalística como sendo uma forma de defender os ideais democráticos, nacionalistas e populares, sendo uma maneira de resistência aos padrões e ao sistema. Posteriormente, na concepção de Aquino:

\footnotetext{
A imprensa alternativa é uma opção na medida em que ocupa, de várias formas, o espaço deixado pelo tipo de imprensa que segue o modelo convencional. [...] A alternativa não se pretende neutra, assumindo-se a serviço da defesa de interesses de grupos como, por exemplo, partidos, sindicatos, associaçóes, minorias raciais e sexuais, e mesmo entidades religiosas. (AQUINO, 1999, p.122)
}

Em relação aos periódicos, Kucinski (2003) estima aproximadamente a criação de 150 jornais de oposição, entre 1964 e 1980. Contudo, por conta da repressão militar e a falta de verba, a perenidade desses tabloides não ultrapassaram cinco anos. Segundo o autor, aproximadamente 25 periódicos alcançaram tal tempo de circulação. De forma que, comparados com a imprensa convencional, os alternativos eram de pequeno porte, não possuíam fins lucrativos, alguns eram produzidos precariamente e raramente possuíam distribuição em escala nacional.

No processo de fundação dos jornais alternativos é possível identificar dois perfis distintos de imprensa: um com viés político/revolucionário e outro com ênfase em questóes socioculturais. Kucinski (2003) explica essas duas categorias. O primeiro grupo propagava ideais de valorização do nacional e do popular, uma herança dos anos de 1950 e do marxismo 
difundido entre os meios estudantis dos anos 60. Com isso, esses periódicos abriram espaço para movimentos populares, reivindicaçôes, protestos e discutiram assuntos pertinentes da esquerda, como a revolução comunista. Além disso, possuíam um caráter marxista e defendiam os preceitos do PCdoB.

A segunda vertente, encontrava suas origens nos movimentos de contracultura norte-americano e eram voltados para a contestação dos valores morais da sociedade, realizan do críticas à hipocrisia da classe média e abordando temas como drogas e sexualidade, sem necessariamente compactuar com o marxismo. Outros tendiam para o anarquismo ou para outras ideologias da esquerda. "A fase de boom da imprensa alternativa coincide, portanto, em grandes linhas com o recrudescimento do Estado autoritário brasileiro pós-64, em que se insere a vigência da censura” (AQUINO, 1999, p. 123).

$\mathrm{Na}$ década de 1960, anos iniciais da imprensa alternativa, ocorreu em meio ao contexto histórico da revolução sexual o surgimento da revista Realidade (1966-1976). A revista por sua vez, mesmo pertencendo à Editora Abril, foi considerada alternativa por $\mathrm{Ku}$ cinski (2003), pois tratava de temas considerados polêmicos para a época, como sexualidade e racismo, além de fomentar discussóes acerca das problemáticas morais e sociais do Brasil. Os jornalistas do editorial da Realidade inspiraram outras criações no meio alternativo, Opinião (1972), Movimento (1975), Assuntos (1976), Um Novo Amanbã (1977), Em Tempo (1977), Bloco (1979), Brasil Extra (1984) e Retrato do Brasil (1987) são exemplos dessa influência.

Posterior à criação da Realidade, surge O Pasquim (1969-1991) que, por sua vez, integrava os jornais alternativos de caráter político. Tratava de assuntos relativos aos problemas sociais do país e expressava sua indignação em relação ao regime civil-militar. Segundo Kucinski:

\begin{abstract}
O Pasquim só surgiu depois que foram fechados três dos principais espaços de humor criados na grande imprensa por Ziraldo, o suplemento "Cartum", do Jornal dos Sports, "O Centavo", no O Cruzeiro e "Manequinho", no Correio da Manhã, todos extintos em 1967. Com o assassinato do jornalista Vladimir Herzog nas câmaras de tortura do Exército, em São Paulo, em outubro de 1975, rompeu-se o precário equilíbrio nas relaçóes de trabalho no conjunto da grande imprensa, ao mesmo tempo em que se esgotou o modo complacente pelo qual os jornais se relacionavam com o regime, dando origem a uma nova geração de jornais alternativos importantes. (KUCINSKI, 2003, p.24)
\end{abstract}

No final dos anos 1970, inspirado em Realidade, porém mais ousado e sofisticado, surgiu o tabloide O Beijo (1977-1978). Em suas publicações abordou de forma crítica e ra- 
dical questóes relativas à sexualidade e, atacou principalmente, os demais jornais alternativos de esquerda que eram considerados conservadores. . "...] O Beijo (1977) foi o primeiro a discutir a sexualidade como principal tema. O jornal lançou o primeiro grande ataque contra o preconceito com que a homossexualidade era tratada[...]” (LIMA, 2001, p.3).

Contudo, o período eleitoral de 1978 marcou o início da abertura política do país. Com a eleição de Ernesto Geisel, o novo presidente prometeu que iniciaria a redemocratização do Brasil, incluindo a liberdade de imprensa. Nessa década em questão, houve o estopim da organização de resistência e mobilização das minorias. Foi durante esse período que grupos acêntricos (feministas, as mobilizações raciais, movimentos de pautas ecológicas, contestações à moral e à sexualidade), tornaram-se predominantes no cenário internacional e no Brasil. "A era das rupturas influenciava o nascimento de uma imprensa altamente especializada, segmentada e de caráter militante” (LIMA, 2001, p. 2). Além disso, o período também as sistiu à formação dos debates sobre a anistia e a redemocratização, conduzindo o regime para $o$ afrouxamento das interfaces repressivas da censura prévia. Desse modo:

Foi nesse contexto de ebulição que, em finais de 1977, alguns intelectuais, jornalistas e artistas homossexuais de São Paulo e Rio de Janeiro reuniram-se [...] a propósito de uma antologia de literatura guei latino-americana, organizada por Winston Leyland, fundador da Gay Sunshine Press, em San Francisco, na Califórnia. [...] surgiu a ideia de se formar um coletivo para a criação de um jornal feito por e com o ponto de vista homossexuais, que discutisse os mais diversos temas e fosse vendido mensalmente nas bancas de todo o país. Aumentado de alguns novos componentes, o grupo se cotizou e o projeto floresceu, com uma periclitante infraestrutura financeira. Em abril de 1978, aparecia então o número zero do jornal Lampião - fato que foi escandaloso para as pudicas esquerda e direita brasileiras, acostumadas ao recato, acima de tudo. (TREVISAN, 2018, p.316-317)

5 Enquanto um novo movimento feminista explodia na Europa desde o começo dos anos de 1970, no Brasil a questão da mulher era desprezada por diversos jornais alternativos importantes. Com a introdução da pílula anticoncepcional e após duas décadas de expansão econômica, ampliou-se a participação da mulher na política institucional e nas atividades produtivas e de direção, ao mesmo tempo em que se aceleraram as transformações na forma da família. Tudo isso desembocou num movimento feminista pela incorporação dessas mudanças no corpo da lei. Questóes da família, do corpo e do sexo tornaram-se públicas. Mas, no Brasil, o feminismo ainda era tratado com desdém e mesmo chacota, inclusive por O Pasquim, que fazia o gênero do jornal machista como parte de sua postura geral "anticlasse média moralista", especialmente através dos artigos de Ivan Lessa, Ziraldo e Paulo Francis. Frequentemente, associavam feminismo à frustração sexual.” (KUCINSKI, 2003, p.124) 


\section{IMPRENSA DAS HOMOSSEXUALIDADES NO BRASIL (LAMPIÃO DA ESQUINA)}

Primeiramente, é de extrema importância salientar que a utilização dos termos guei $^{6}$ e homossexualidades, utilizados para se referir aos grupos de resistência e de imprensa em questão, foram escolhidos com o intuito de se aproximar da realidade do período estudado. Em conformidade com Quinalha (2018) e Rodrigues (2010), a intenção não é propagar a exclusão dos demais membros da comunidade LGBTQ+. A termologia:

\footnotetext{
"Homossexualidades" era o termo utilizado até começo dos anos 1990 para se referir ao conjunto de orientações sexuais e identidades de gênero consideradas não normativas ou dissidentes. Assim, naquele momento da ditadura, as travestilidades e transgeneridades eram compreendidas nessa designação mais ampla de "homossexualidades", inclusive por travestis, daí o seu uso no plural para sinalizar essa abrangência. (QUINALHA, 2018, p.15).
}

Posto tais esclarecimentos, durante o período das décadas de 1970 e 1980 ocorreu de forma similar e conjunta a formação da imprensa homossexual e do movimento de resistência guei no Brasil. As personalidades pertencentes à formação desses grupos - que almejavam se consolidar em meio à sociedade autoritária e conservadora - contribuíram igualmente para a criação de tabloides homossexuais. Com o objetivo de ampliar a representatividade des sa minoria na imprensa alternativa, a intenção era fomentar um "espaço de fala”. Nesse contexto:

\footnotetext{
A imprensa dirigida aos homossexuais no Brasil, como no mundo, surge da necessidade que uma parcela da sociedade teve de procurar seus semelhantes, buscar uma união com os iguais, construir um refúgio coletivo, lutar contra um sistema que os tornava invisíveis. (RODRIGUES. 2018, p. 237)
}

De acordo com o levantamento realizado por Lima (2001) ao analisar o Lampião, durante os anos 1960 e 1970 existiram no Rio de Janeiro um número aproximado de quinze jornais com temática guei em circulação. Alguns títulos eram o Snob, Gilka Dantas, Le Femme, Subúrbio à Noite, Gente Gay, Aliança de Ativistas Homossexuais, Eros, La Saison,

6 Assim como Trevisan em Devassos no Paraíso, será empregado nesse artigo o termo "guei” e não "gay”, a fim de aportuguesar os termos. Contudo, em citaçóes será mantido da mesma forma em que o citado escreveu. 
O Centauro, O Vic, O Grupo, Darling, Gay Press Magazine, 20 de Abril, O Centro e O Galo. Em Niterói, surgiram Os Felinos, Opinião, O Mito e Le Sophistique.

Os autores Rodrigues (2018) e James N. Green (2018), abordam as relações existentes entre a prematura imprensa alternativa guei e o movimento de resistência, que houve no país nos anos de 1960 a 1980. Em 1978, junto a outros ativistas do Brasil, como João Silvério Trevisan ${ }^{7}$, Green participou do nascimento do então Núcleo de Ação para os Direitos dos Homossexuais, que foi chamado, a partir de 1979, SOMOS. Em conformidade com as atividades do grupo:

A primeira ação do grupo foi justamente enfrentar a ideologia anti-homossexual, cujas manifestações discursivas mais agressivas apareciam na imprensa marrom, especificamente no caso de São Paulo nos retratos estereotipados de homossexuais nas páginas do jornal Notícias Populares. Embora a carta enviada aos diretores deste jornal sensacionalista não mudasse a sua linha editorial, a orientação do grupo representava uma tentativa de sensibilizar a sociedade e os meios de comunicação. (GREEN. 2018, p.71)

Assim sendo, surge em abril de 1978, o primeiro alternativo destinado para as homossexualidades, o jornal Lampião da Esquina. Desse modo, em conformidade com Bandeira (2006), o Lampião realizou suas três primeiras edições com o dinheiro arrecadado por doações dos editores e da comunidade guei, sendo que suas publicaçóes posteriores foram mantidas pelas vendas e assinaturas do tabloide ${ }^{8}$.

O nome do mensário, segundo Bandeira (2006), possuía uma dupla simbologia. A primeira, seria referente ao equipamento "lampião" utilizado para a iluminação, uma analogia aos objetivos do jornal, ou seja, o de iluminar os caminhos dos homossexuais. A outra alegoria, relaciona-se com o personagem nordestino Virgulino Ferreira da Silva, vulgo Lampião, por conta de sua representatividade da virilidade masculina e do machismo do século XX. Além disso, o termo "esquina" buscava simbolizar os guetos dos homossexuais, dos quais eram espaços marginalizados e excluídos da sociedade. Com isso:

O que Lampião da Esquina pretendia com sua "luminosidade" e sua "macheza" era mostrar a homossexualidade segundo novas perspectivas, assumindo o lugar de

7 João Silvério Trevisan foi um dos editores e fundadores do jornal Lampião da Esquina, sendo mais um exemplo da aproximação entre o surgimento da imprensa guei e a resistência dessa minoria.

8 Segundo Aquino (1999), a imprensa alternativa era sustentada financeiramente da venda das bancas, das assinaturas e das doaçốes de simpatizantes e associados. 
Na escuridão da censura, surgiu uma luz: Lampião da Esquina e a imprensa alternativa (1978-1981)

homossexual sem ter que abdicar do papel de homem "de verdade" e delineando um projeto de assunção gay caracterizado por formas positivas de dizê-la. (BANDEIRA, 2006, p.36)

Os editores e fundadores do Lampião eram intelectuais, jornalistas e ativistas homossexuais de São Paulo e do Rio de Janeiro. Suas publicações, valiam-se da linguagem dos guetos homossexuais dessas duas cidades. Dentre os membros fundadores do periódico, estão: Aguinaldo Silva, Antônio Chrysóstomo, Clóvis Marques, Darcy Penteado, Francisco Bittencourt, Gasparino Damata, Jean Claude Bernardet, João Antônio Mascarenhas, João Silvério Trevisan e Peter Fry.

O periódico homossexual abordava temas como sexualidade, racismo, artes, ecologia e machismo, além de empregar um vocabulário considerado impróprio e pejorativo para a heteronormatividade, como "viado" e "bixa”. O jornal tinha por objetivo, segundo Trevisan (2018), ressignificar palavras preconceituosas dirigidas contra as homossexualidades e usá-las como uma forma de aceitação e resistência. Ademais, o Lampião buscou quebrar paradigmas conservadores da sociedade da época, trabalhando principalmente com a conexão existente entre as minorias brasileiras. Nas palavras do ativista Green:

[...] na época não circulava uma teoria sobre as interseccionalidades das identidades e lutas ou sobre as relaçóes e conexões entre o movimento sindical e os movimentos de feministas e de negr@s ou outros processos de lutas democráticas [...]. Ou seja, não havia no Brasil no sentido de que uma pessoa poderia ser homossexual e operária ou lésbica e negra. (GREEN, 2018, p.73)

O jornal Lampião possuía como característica seriedade na maneira pela qual tratava suas informações, o diferenciando, na perspectiva de Bandeira (2006), de jornais que o antecederam. As matérias das publicações mesclavam as concepções do gueto guei com os pensamentos de seu Conselho Editorial, "tratava-se de um jornal que desobedecia em várias direçôes” (TREVISAN, 2018, p.317), de modo a contestar o regime ditatorial, mas também as concepçôes tradicionais e conservadores da sociedade e do movimento de esquerda do país. No entanto, o projeto de articulação das lutas das minorias não deu certo no jornal. A união entre as pautas do movimento negro, feminista, indígena e ecológico não ocorreu. Lampião assumiu, predominantemente, um papel com as homossexualidades. Nessa concepção:

No seu curto tempo de vida, o Lampião iluminou o caminho de várias pessoas que viviam à sombra de sua própria existência. Foi importante para toda essa geração 
que pôde ver que não estava sozinha, que não era louca nem doente e que existia um outro lado, uma outra possibilidade identitária. (RODRIGUES, 2018, p.242)

Lendo a seção "Saindo do Gueto" é possível perceber alguns dos objetivos da criação desse jornal. De modo geral, o intuito era proporcionar um portal de voz para os homossexuais marginalizados na sociedade brasileira, sendo os mesmos que sofriam com as agruras do preconceito e da homofobia. O Lampião, que a partir da edição de no 1 passou a se intitular Lampião da Esquina, buscava tratar de temas considerados "secundários" para os debates políticos do período, de modo a engajar no cenário nacional essas temáticas:

\begin{abstract}
Para acabar com essa imagem-padrão, LAMPIÃO não pretende soluçar a opressão nossa de cada dia, nem pressionar válvulas de escape. Apenas lembrará que uma parte estatisticamente definível da população brasileira, por carregar nas costas o estigma da não reprodutividade numa sociedade petrificada na mitologia hebraico cristã, deve ser caracterizada como uma minoria oprimida. E uma minoria, é elementar nos dias de hoje, precisa de voz. (LAMPIÃO, 1978, p. 2)
\end{abstract}

Em acréscimo ao exposto, segundo Lima, o tabloide Lampião realizava em suas publicaçôes algumas notas de repúdio, que por sua vez eram semelhantes às açôes relatadas anteriormente por Green sobre o grupo SOMOS:

Pequenas notas contra os atos preconceituosos da sociedade eram constantes. Assim como ataques diretos a homófobos ou quem agisse de modo politicamente incorreto (embora não se usasse tal terminologia à época) em relação aos homossexuais. (LIMA, 2001, p.

Em conformidade com Rodrigues (2010), diferentemente da imprensa guei norte-americana, as produções de periódicos no Brasil de temática semelhante não se preocupavam com questóes envoltas aos critérios estéticos do design. O tabloide Lampião não fugia a essa regra brasileira.

Com manchas gráficas pesadas, poucos claros, uma diagramação dura e de pouco inventividade, o jornal tinha como preocupação maior seu discurso verbal. Diferentemente das primeiras publicaçóes americanas, que valorizavam o papel do design gráfico nos periódicos, no projeto gráfico do jornal Lampião a transgressão não foi priorizada, apesar de contar com um artista plástico entre seus editores. (Rodrigues, 2010, p. 406-407) 
O Lampião da Esquina era realizado em forma de tabloide e constituído das seções Cartas na Mesa, Esquina, Reportagem, Tendências e Bixórdia, assim sendo: "Cartas na Mesa” era um espaço destinado a publicação de cartas dos leitores e respondidas pelos editores; a "Esquina” trazia notícias relativas à comunidade homossexual; "Reportagem” realizava entrevistas com personalidades do período, abordando temáticas sobre as minorias e o regime político vigente; havia um espaço destinado para indicações e comentários referente ao Cinema, Literatura, Música e Teatro, reunidos sob a rubrica "Tendências"; por fim, "Bixórdia" possuía um caráter humorístico, porém seu surgimento ocorreu só após a edição de número nove. Desse modo, as edições possuíam uma média de 16 a 20 páginas. É possível encontrar nas páginas do tabloide algumas charges, fotos de personalidades entrevistadas ou ensaios fotográficos de homens nus, anúncios publicitários de estabelecimentos e de divulgação dos livros publicados por alguns dos editores do jornal. Segundo Simões Júnior (2006), as impressões eram feitas em cores neutras.

Em consonância com o que já foi relatado sobre a censura, no mês de agosto de 1978, o jornal Lampião foi processado pelo Ministério da Justiça com a acusação de ferir as condutas morais socialmente aceitas. Referindo aos membros do Conselho Editorial, a carta entregue pela Polícia Federal dizia que os organizadores do jornal eram "pessoas que sofriam de graves problemas comportamentais" (TREVISAN, 2018, p. 323). O periódico foi enquadrado na Lei de Imprensa; segundo Trevisan, o principal argumento judicial de acusação era a reportagem escrita por ele mesmo sobre o caso do jornalista Celso Curi ${ }^{9}$, publicado na edição de número zero. Tanto o jornalista Curi como o corpo editorial de Lampião da Esquina foram absolvidos das acusaçóes e os casos foram arquivados.

\section{MOTIVOS QUE PROMOVERAM O FECHAMENTO DO LAMPIÃO DA ESQUINA E DE OUTROS ALTERNATIVOS}

O fechamento dos jornais alternativos não se deu apenas por conta da repressão e da censura. Kucinski (2003) concorda com Ana Maria Nethol quando ela afirma que a im-

9 “[...] o caso do jornalista Celso Curi, que desde 1977 vinha sendo processado pelo mesmo motivo: ofensa à moral e aos bons costumes - dessa feita através de uma coluna de temática homossexual, a famosa "Co luna do Meio", publicada diariamente no antigo jornal Última Hora, de São Paulo, em que se promoviam "encontros entre anormais”, segundo o promotor público”. (TREVISAN, 2018, p.324) 
prensa alternativa criou um "modelo ético-político" próprio, no qual repudiava o lucro e os preceitos capitalistas, resultando na vulnerabilidade financeira. Além disso, o autor acrescenta que com o enfraquecimento do controle às mídias, a imprensa convencional poderia realizar críticas e ataques ao governo, tirando o protagonismo dos demais jornais não convencionais.

Ademais, o fim da imprensa alternativa não se dá apenas pela repressão do regime militar, mas também pelos conflitos internos existentes nos periódicos e na esquerda brasileira. Se colocado em consideração os objetivos iniciais que levaram à formação dos tabloides alternativos, é possível constatar que tais publicações surgiram como um projeto de resistência à opressão militar, com o fim de tal contexto histórico, a fundamentação de tal propósito é encerrado, diminuindo a necessidade do número de periódicos desse seguimento.

Segundo alguns autores, como Lima (2001) e Kucinski (2003), o Lampião da Esquina deu início a seus trabalhos com um caráter sofisticado e fortemente político, contudo passou a ter um viés cada vez mais erótico e menos crítico da sociedade em suas últimas edições, “Lampião [...] começou elegante e terminou pornográfico” (KUCISNKI, 2003, p. 132). Essas afirmações são baseadas no contexto histórico dos últimos anos do jornal, no qual se refere ao momento em que a sociedade estava passando pela erotização das produçôes midiáticas e o mercado pornográfico estava conquistando cada vez mais adeptos. Lima considera que como as produções pornográficas eram mais baratas que o Lampião as vendas do mesmo caíram, ou seja:

A partir daí, a imprensa homossexual brasileira foi tomada pelo pornográfico. Dezenas de publicaçôes surgiram explorando o nu masculino. Primeiramente, disfarçadas em revistas como Naturismo, que pregava a vida saudável e o fisiculturismo; aprimorou-se, depois, em publicações específicas, especialmente em São Paulo. Surgiram as revistas Gato, Alone Gay, Young Pornogay, entre outros títulos. (LIMA, 2001, p. 4)

Nessa mesma perspectiva e com o aumento de materiais impressos com temáticas acerca das homossexualidades, o Lampião encerra suas atividades em julho de 1981. No que se refere às causas do fechamento do jornal, segundo Trevisan, está a fragmentação do público que acompanhava o Lampião. Assim, tornou-se comum os jornais, como o Folha de S. Paulo, realizarem matérias sobre sexualidade. Ademais, com as divergências políticas existentes dentro jornal, por conta da eclosão de manifestações ideológicas inconsonantes acerca da Anistia, do movimento homossexual, feminista e da esquerda em geral, fizeram com que se optasse pelo fim do Lampião da Esquina. 
Inferindo tais ideias expostas, é possível perceber que o regime militar proporcionou de maneira indireta a criação de novas maneiras de se realizar a imprensa. A censura, a repressão à informação e aos intelectuais da época, fizeram com que surgissem os alternativos, os quais foram de extrema importância para a história do país, possibilitando, na atualidade, a compreensão dos movimentos de luta e resistência do período.

Ademais, como foi dito ao longo do artigo, nesse mesmo contexto outros movimentos subversivos surgiram em meio à Ditadura. O SOMOS e o Lampião da Esquina são os exemplos tratados aqui, suas criaçóes proporcionaram a constituição da luta articulada em prol das homossexualidades, que por sua vez, seriam no século XXI a comunidade LGBTQ+. Contudo, é compreendido que esse ensaio não trabalhou por completo todas as especificidades da formação histórica das resistências lésbicas, gueis, bissexuais, transexuais, travestis, transgêneros, intersexuais, dentre outros. O Lampião e o SOMOS são apenas uma parcela de uma grande luta contra o machismo, misoginia, homofobia, transfobia e o conservadorismo.

Em tese, é perceptível que os movimentos de contestação à realidade social são questionadores à ordem vigente, pois contrapóem e proporcionam mudanças significativas em meio à sociedade, inspirando sempre novas pessoas a se articularem em prol de lutas e resistências. Quando criada, a imprensa trouxe novas maneiras de se fazer e divulgar notícias. Tempos depois, no Brasil, ocorreu o surgimento dos alternativos, marcando mais uma vez as inovações acerca da história da imprensa. E nesse mesmo período, nasceu outro segmento, os tabloides de liberdade sexual, como o Lampião da Esquina. Em outras palavras, sempre é possível que haja um movimento insurgente dentro de outro. 


\section{REFERÊNCIAS BIBLIOGRÁFICAS}

AQUINO, M. A de. Censura, Imprensa e Estado autoritário (1968-1978): o exercício cotidiano da dominação e da resistência. Bauru, SP: EDUSC, 1999.

BANDEIRA, M. L. G. Será que ele é?: Sobre quando Lampião da Esquina colocou as Castas na Mesa. São Paulo, SP: PUC, 2006. Dissertação (Mestrado em História) - Pontifícia Univer sidade Católica de São Paulo, São Paulo, 2006.

BARBOSA, M. História cultural da imprensa: Brasil, 1900/2000. - Rio de Janeiro, RJ: Mau$\operatorname{ad} X, 2007$.

GREEN, J. N. Forjando alianças e reconhecendo complexidades: as ideias e experiências pioneiras do Grupo Somos de São Paulo. In GREEN, J. N.; QUINALHA, R.; CAETANO, M.; FERNANDES, M. (Org.). História do Movimento LGBT no Brasil. 1. ed. São Paulo, SP: Almeida, 2018, p.63-78.

KUCINSKI, B. Jornalistas e revolucionários: nos tempos da imprensa. 2. ed. ver. e ampl. São Paulo: Editora da Universidade de São Paulo, 2003.

LAMPIÃO, Rio de Janeiro, edição experimental, no 0, abr. 1978.

LIMA, M. A. A. Breve histórico da imprensa homossexual no Brasil. Biblioteca online de ciências e computação, 2001. Disponível em: http://www.bocc.ubi.pt/_esp/autor.php? codautor=606. Acesso em: 21 mar. 2019.

PINAFI, T. Assimetrias de Poder na Militância entre Gays e Lésbicas. In: COSTA, H. (Org.). Retratos do Brasil homossexual: fronteiras, subjetividades e desejos. São Paulo, SP: Edusp, 2010, p.333-342.

QUINALHA, R. Uma ditadura hetero-militar: notas sobre a política sexual do regime autoritário brasileiro. In: GREEN, J. N.; QUINALHA, R.; CAETANO, M.; FERNANDES, M. (Orgs.). História do Movimento LGBT no Brasil. 1. ed. São Paulo, SP: Almeida, 2018, p.1538. 
RODRIGUES, J. C. A imprensa gay no Brasil. In: GREEN, J. N.; QUINALHA, R.; CAETANO, M.; FERNANDES, M. (Org.). História do Movimento LGBT no Brasil. 1. ed. São Paulo, SP: Almeida, 2018, p.236-253.

RODRIGUES, J. C. Os caminhos da Imprensa Gay Nacional. In: COSTA, H. (Org.). Retratos do Brasil homossexual: fronteiras, subjetividades e desejos. São Paulo, SP: Edusp, 2010, p.403-412.

SIMÕES JR., A. C. E havia um lampião na esquina: memórias, identidades e discursos homossexuais no Brasil do fim da ditadura (1978-1980). Rio de Janeiro, RJ: UNIRIO, 2006. Dissertação (Mestrado em Memória Social) - Universidade Federal do Estado do Rio de Janeiro, 2006.

TREVISAN, J. S. Devassos no Paraiso: a homossexualidade no Brasil, da colônia à atualidade. 4. ed, ver., atual. e amp. Rio de Janeiro, RJ: Objetivo, 2018. 